\title{
Commercialization policy of inventions for green growth target
}

\author{
Phan Quoc Nguyen, PhD. \\ Department of Civil Law, School of Law, \\ Vietnam National University, Hanoi, Vietnam \\ Nguyen Vinh Hung, PhD. \\ Department of Civil Law, School of Law, \\ Vietnam National University, Hanoi, Vietnam
}

\begin{abstract}
This paper examines the commercialization policy of inventions from research findings towards green growth in Vietnam. The invention commercialization is very important for the economic development in Vietnam. The Government plays the essential role to promote the activities through her policy and support units. This paper also gives some solutions to enhance the role of the Government as policy makers and information providers to promote the commercialization of inventions from research findings in the statu quo for the greening growth target.
\end{abstract}

Key words: commercialization policy of inventions/research findings, green growth, intellectual property (IP), science and technology (S\&T), technology transfer (TT)

JEL codes: K2, 03, Q5

\section{INTRODUCTION}

Commercialization policy of inventions from research findings is imperative for the economic development to the green growth. The Government plays very important role in launching commercialization policy of inventions and in establishing support units. In addition, the Government is also the support tools, such as capital investment, and is the place for storing and supplying information on important research findings.

The Government through its agencies considered being the focal places for of invention commercialization is playing the role of a keeper and provider of an abundant source of information for this activity. However, this source of information has not been effectively exploited. The application centers themselves store such information but have not been able to exploit the information to its potential.

Some solutions are necessary to enhance the role of the Government as policy makers and information providers to promote the commercialization of inventions from research results in the current state of being "kept dormant" for the green growth.

\section{RELATIONSHIP BETWEEN COMMERCIALIZATION POLICY OF INVENTIONS/RESEARCH FINDINGS AND GREEN GROWTH}

Commercialization of inventions/research findings plays a very important role for economic development in general and for green growth in particular. Invention means a technical solution in the form of a product or a process which is intended to solve a problem by application of laws of nature ${ }^{1}$. Therefore, invention is intellectual product and asset. In addition, invention is tranferable and has all characteristics of a good. Inventions are patented 
if they satisfy all patentability conditions. Therefore, they could bring profits for owners if they are exploited, managed and used properly. In fact, commercialization of inventions and research findings play important role for green growth of each country. In particular, commercialization of inventions fosters innovation, raises inner capacity of technology, promotes invention transfer for green growth.

\section{THE IMPLEMENTATION OF INVENTION COMMERCIALIZATION POLICY FOR GREEN GROWTH}

\section{The policy of green growth}

Green growth is the option by many countries in the world, including Vietnam, nowadays. In order to push the process of green growth, nothing is better than commercialization policy of inventions. Using clean technology, transferring technology of renewable energy, applying new production process, consuming less energy, saving natural resources, reducing greenhouse gas emission are typical examples for green growth. In Vietnam, green growth target was first officially mentioned in the Resolution of the Party's Congress XI in 2011 and was consistently followed in the Resolution of the Party's Congress XII in 2016 with the emphazise on the green growth target; development of clean energy, clean production, clean consumption ${ }^{2}$. Therefore, the State and Government have issued many policies to promote the development of science and technology (S\&T) in order to accelerate the national economic development. The Government also has policy to develop and commercialize invention and intellectual property (IP)"3.

To promote S\&T activities in general and commercialization of inventions/research findings in particular, in recent years, the National Assembly, the Government and other authorities have issued many legal documents and related policy, gradually setting up mechanisms to promote their commercialization.

According to the surveys and assessment of the Ministry of Science and Technology (MOST), the legal system of S\&T is basically completed in accordance with a modern management model that has been successful in many developed countries such as Japan, Germany, Korea and China, etc ${ }^{4}$.

To date, Vietnam has 8 specialized laws and supporting legal documents that were enacted: the Law on Science and Technology (2000, amended in 2013); Law on Intellectual Property (2005, amended in 2009); Law on Standards and Technical Regulations (2006); Law on Technology Transfer (2006, amended in 2017); Law on Product and Good Quality (2007); Law on Atomic Energy (2008); Law on High Technology (2008) and Law on Measurement (2011). The MOST have submitted to the Government and the Prime Minister to issue more than 50 decrees and decisions to guide law implementation.

Some important laws marking the change and renovation of mechanisms related to research, technology transfer (TT) and IP rights include the Law on S\&T, Law on TT, Law on IP Rights, etc. along with many legal documents on S\&T that were issued. They basically created a legal framework for the implementation of State management over S\&T activities of all economic sectors in the market economy and international integration, while encouraging economic players to invest in scientific research and the technology application at universities, institutes,

\footnotetext{
2 Documents of National Party Congress XI and XII.

3 Strategy for socio-economic development from 2011 to 2020.

${ }^{4}$ Report No. 842/BKHCN-KHTC dated on 05/4/2012 of MOST on the implementation of policy on investment in S\&T, submitted to National Assembly.
} 
especially to promote the development of the technology market, enhancing the competitiveness of enterprises. These include a number of important documents such as: Decree No. 115/2005/ND-CP on the autonomy and self-responsibility of public S\&T organizations, Decree No. 80/2007/ND-CP on technology-based enterprises, Decree No. 96/2010/ND-CP amending and supplementing Decree No. 115/2005/ND-CP and Decree No. $80 / 2007 / \mathrm{ND}-\mathrm{CP}$, the decision of the Prime Minister promulgating the Regulation on management process for the Program to support IP of enterprises"; Joint Circular No. 102/2006/TT-BTC-BHCN 31/10/2006 of the Ministry of Finance and MOST guiding the financial management support for Program to support IP of enterprises.

Even while giving tasks to implement national programs or state-level S\&T programs, the Government also requires that each S\&T task can only be completed when achieving the following specific targets (2011-2020): a/ By 2020, S\&T will contribute a significant part to the economic growth and restructure of the economy, value of hi-tech products and hi-tech application products will account for about 45\% of the GDP. The speed of technology and equipment innovation will reach at 10-15\%/year for the 2011- 2015 period and over 20\%/year for the 2016-2020 period. Transaction value of the S\&T market will increase 15$17 \% /$ year on the average.

b/ The number of international announcements from research themes funded by the State budget will increase 15-20\%/year on the average. The number of innovations registered for protection for the 2011-2015 period will increase 1.5 times higher as compared to those of the 2006-2010 period and the number of the 2016-2020 period will be twice higher than that of the 2011 - 2015 period, especially the number of innovations innovated from State key S\&T programs will be increased fast.

c/ It is strived to increase the total social investment in S\&T at the level of $1.5 \%$ of the GDP by 2015 and over $2 \%$ of the GDP by 2020 . It is ensured that investments from the State budget in S\&T reach at least $2 \%$ or more of the total annual State budget expenditure.

d/ By 2015, the number of officers in charge of scientific research and technological development will reach 9-10 persons per ten thousand people; training and examination are of the international standards, 5,000 engineers are fully capable of managing and operating hitech production lines of the country's branches and fields of development priorities.

By 2020, the number of officers in charge of scientific research and technological development will reach 11-12 persons per ten thousand people; training and examination are of the international standards, 10,000 engineers are fully capable of managing and operating hi- tech production lines of the country's branches and fields of development priority.

dd/ By 2015, 30 basic research and use organizations of the regional and international levels, which are fully capable of solving issues of national importance relating to science and technology; 3,000 S\&T enterprises; 30 hi-tech technology incubators and hi-tech enterprise incubators will be formed.

By 2020, 60 basic research and use organizations of the regional and international levels, which are fully capable of solving issues of national importance relating to S\&T; 5,000 S\&T enterprises; 30 hi-tech technology incubators and hi-tech enterprise incubators will be formed.

In fact, thanks to changes in policies, the technology market has new developments compared the previous period: the number of technology transactions in the period 2006-2010 increased 
more than three times, and the total value of transactions through contracts signed increased 2.5 times compared to the period 2001-20055.

In the period 2011-2016, the annual investment for S\&T activities was at $2 \%$ of the total State budget expenditures (equivalent to 0.5 to $0.6 \%$ GDP with the average growth rate of about $16 \%$ per year; the state budget is still the main source of investment, accounting for $70 \%$ of the total investment of the whole society for S\&T activities). In addition to the state budget, S\&T investments also come from many different sources in the society 6 .

It can be confirmed that the role of the State and Government are significant in making national policy for scientific research and commercialization of scientific products. Reality has proved that when the State policy is linked to real life practices, it will promote rapid development of transactions in the economy (and vice versa).

\section{The practical implementation of green growth policy}

As stated above, the role of the State in the commercialization of inventions/research findings is not only reflected in its policy-making role or role of an investor, but it also provides information to support the exploitation of information on inventions and research findings, and is also where the commercial deployment for this target group takes place. In details, some Government's agencies considered to be the focal places for commercialization of inventions and research findings.

These focal places are agencies under the MOST (National Agency for Science and Technology Information and National Office of Intellectual Property). With their role, these agencies have been implementing a number of functions, tasks and measures to exploit and commercialize inventions and research results. They are management agencies that implement and enforce policies issued by the Government, and in many cases they are advisory bodies and issue policy related to this activity.

The National Agency for Science and Technology Information as a focal organizer for the technology and equipment market (Techmart), the largest place for storage and management of S\&T information in Vietnam, covering most of the natural sciences, engineering science and technology fields important for the development of S\&T.

Every year, the National Agency for Science and Technology Information (the focal agency under the MOST) organizes Techmarts with the aim of promoting and introducing technology products for people with products and people wishing to use them. The purpose of these Techmarts is to strengthen the linkage between research and training with production and business, foster the commercialization of S\&T results, and promote technology transfer in the country. Currently, the website of the National Agency for Science and Technology Information stores a considerable amount of information on sale offers as well as demand for technological equipments, in mainly fields: information technology and telecommunications; mechanicalengineering; electrical-electronic-automation; agriculture; and raw materials-chemicalpharmaceutical products ${ }^{7}$.

\footnotetext{
5 http://www.baotintuc.vn/131N20120130182458842T0/phat-trien-thi-truong-cong-nghetiep-suc-thuong-maihoa-san-pham-khoa-

hoc-cong-nghe.htm.

6 UNESCAP, Infrastructure Financing Strategies for Sustainable Development in Viet Nam, 15 September 2017.

${ }^{7}$ See more on website: http://www.techmartvietnam.vn.
} 
The establishment of a "market" for technology as currently done by the National Agency for Science and Technology Information is an important source of information for businesses and researchers to learn about the market and the market demand.

National Office of Intellectual Property (NOIP) is the management agency for information data on inventions that have been registered for patent protection, which provides patent information, perform registration of patent licensing and transfer.

By the end of 2010, the NOIP has kept 26,516,121 invention descriptions and 1,539,476 utility solution descriptions. In 2011, it added 1,018,243 invention descriptions and 16,938 utility solution descriptions. Thus, by the time the end of 2011, the Office has preserved 29,090,778 descriptions of inventions and utility solutions ${ }^{8}$. This is an extremely rich source of information kept by a professional agency and has a potential if exploited for commercialization.

In the 2008-2011 periods, the NOIP dealt with 598 requests to search for patent information and provided more than 70,338 pages of invention descriptions for the users ${ }^{9}$. This number is too low. Based on findings on the need of transferring and applying inventions to be supported in the framework of the Program to support intellectual property of enterprises (Program 68), the commercialization of the inventions that are patented in Vietnam at present is very limited (according to Mr. Ta Quang Minh, Head of National Office of Intellectual Property) ${ }^{10}$. The number of green technologies patented is even smaller, which accounts for $2.57 \%$ out of total patents of technologies ${ }^{11}$.

\section{SOME COMMENTS AND RECOMMENDATIONS}

The role of the Government in the commercialization of inventions/research findings is shown most clearly in the role of a policy maker, which is one of the most important tasks/role of the State. However, at present these policies are not good but do not still meet the requirements derived from those abide by or benefit from it (mostly businesses and research entities such as universities/research institutes). Obviously, to promote the exploitation and commercialization of inventions and research results, these entities cannot be lacked.

Based on the above analysis, the commercialization of inventions and research findings mainly takes place through technology markets or exhibitions (for businesses).

Therefore, the Government needs to encourage more different parties to connect with each other. The current situation show that the researchers study those issues that do not come from the needs of businesses and markets, while businesses themselves can only find production solution through self-research efforts or import of appropriate technologies. This is wasteful for production and makes the State policy for S\&T less effective.

Apart from the role to make policy for the commercialization of research findings and to be an investor for this activity, the State and Government (through its agencies) are playing the role of a keeper and provider of an abundant source of information for this activity. However, this source of information has not been effectively exploited. The application centers themselves store such information but have not been able to exploit the information to its potential. There

\footnotetext{
${ }^{8}$ Report by the IPP project, conducted by NATEC, MOST, 2013.

${ }^{9}$ As above.

${ }^{10}$ According to the reports by the NOIP regarding invention activities from 2008 to 2011, uploaded on: http://www.noip.gov.vn.

${ }^{11}$ Complied from NOIP's Gazettes in 2011.
} 
are many causes for this ineffective exploitation, one of which is probably derived from the inconsistent and unsystematic operation of the management agencies which have not foster the advertisement and introduction of necessary information to the appropriate audience.

Thus, the commercialization of inventions and research findings in practice has received participations from different entities (enterprises and research institutes/universities), but in many cases seem to lack the involvement of the Government. Therefore, the Government needs to make the general policy and provide resources for research and commercialization activities more efficient in fulfilling her role in creating linkages and promoting the commercialization of inventions and research findings. The role of Government is to stand next to the enterprises and research institutes /universities.

Based on the above analysis, in order to promote the commercialization of inventions and research findings and to implement the connection model (state enterprises - universities /institute) effectively, it is necessary for the Government to carry out a number of solutions:

\section{The policy:}

Develop regulations on assessment and valuation of IP, transfer and capital contribution to enterprises by IP. Improve the policy to support the identification and protection of intellectual property rights and the completion and commercialization of products and at the same time promote investment and branding of products from the S\&T research results. Establish TT organizations in universities and research institutes.

Develop policy on ownership of research results generated from scientific research and technological development activities using state budget for the organization chairing S\&T tasks; and mechanism on benefit sharing between State agencies and authors.

\section{The information provision:}

Develop statistical indicators to measure the results and effectiveness of S\&T activities. Develop a national database system on technology, technology expert and supply-demand of technology.

\section{References:}

IP Law of Vietnam (2005, amended in 2009).

Official Gazettes of NOIP from 2011 to 2018.

Report No. 842/BKHCN-KHTC dated on 05/4/2012 of MOST on the implementation of policy on investment in S\&T, submitted to National Assembly.

Report by the IPP project, conducted by NATEC, MOST, 2013.

Resolutions of the Party's Congress XI in 2011 and XII in 2016.

Strategy for socio-economic development from 2011 to 2020.

UNESCAP, Infrastructure Financing Strategies for Sustainable Development in Viet Nam, 15 September 2017.

Available online at: http://www.baotintuc.vn/131N20120130182458842T0/phat-trien-thi-truong-congnghetiep-suc-thuong-mai- hoa-san-pham- khoa-hoc-cong-nghe.htm.

Available online at: http://www.techmartvietnam.vn.

Available online at: http://www.noip.gov.vn. 